\title{
How to measure disease activity in eosinophilic esophagitis
}

\author{
A. Schoepfer, ${ }^{1}$ E. Safroneeva, ${ }^{2}$ A. Straumann ${ }^{3}$ \\ ${ }^{1}$ Division of Gastroenterology and Hepatology, Centre Hospitalier Universitaire Vaudois (University Hospital \\ Lausanne), Lausanne, ${ }^{2}$ Institute of Social and Preventive Medicine, University of Bern, Bern, and ${ }^{3}$ Praxis \\ Römerhof, Swiss EoE Clinic, Olten, Switzerland
}

\begin{abstract}
SUMMARY. Activity of Eosinophilic Esophagitis (EoE) can be measured by patient reported outcomes (symptoms and quality of life) and clinician-reported outcomes (endoscopic, histologic, or biochemical alterations). Over the last years efforts have been underway to develop and validate instruments to assess EoE activity in the different domains. Such instruments are urgently needed to standardize the language of EoE activity assessment and, in so doing, to facilitate communication among various stakeholders. Such standardization will ultimately allow EoE researchers to define meaningful endpoints for use in clinical trials and observational studies, to compare the efficacy of different therapeutic modalities, and to develop algorithms in order to provide patients with the appropriate therapy. This review provides an overview of the current status of instruments that assess EoE activity in the different domains.
\end{abstract}

KEY WORDS: eosinophilic esophagitis, patient reported outcomes, quality of life, eosinophils, disease activity.

\section{INTRODUCTION}

Why is it important to measure EoE activity?

Eosinophilic esophagitis (EoE) has first been recognized as distinct disease entity in the early $1990 \mathrm{~s} .{ }^{1,2}$ An increasing incidence and cumulative prevalence of EoE has been noted in industrialized countries with current incidence rates of about 1 new patient in 10,000 inhabitants per year and current prevalence rates of approximately 1 patient per 2000 inhabitants. ${ }^{3-6}$ The first comprehensive definition of EoE was published in 2007.7 In the updated 2011 version, EoE was defined by a panel of international

Address correspondence to: Dr Alain Schoepfer, MD, PD + MER1, Division of Gastroenterology and Hepatology, Centre Hospitalier Universitaire Vaudois/CHUV, Rue de Bugnon 44, 07/2409, 1011 Lausanne, Switzerland. Email:

alain.schoepfer@chuv.ch

Disclaimers: The authors are among the copyright holders of the Eosinophilic Esophagitis Activity Index (EEsAI) Patient Reported Outcomes Instrument that is copyrighted by University of Bern, Switzerland. Please contact the corresponding author for questions regarding the use of the EEsAI PRO instrument for clinical trials.

Grant support: This work was supported by a grant from TIGERS (The International Gastrointestinal Eosinophil ResearcherS) and the Swiss National Science Foundation (Grant No. 32003B_135665/1 to AMS and AST).

Conflict of interest: None related to this manuscript. experts as 'a chronic, immune/antigen-mediated, esophageal disease, characterized clinically by symptoms related to esophageal dysfunction and histologically by eosinophil-predominant inflammation'. ${ }^{8}$ Other conditions associated with esophageal eosinophilia, such as gastroesophageal reflux disease (GERD), Crohn's disease, or achalasia, should be excluded before EoE can be diagnosed.

Given the fact that EoE has been first described a little over 20 years ago, it is not astonishing that until recently, no validated instruments to assess different aspects of EoE activity existed. The use of different, either non-EoE-specific or non-validated, instruments to assess EoE symptom severity may explain why a dissociation between EoE symptom severity and histologic activity has been documented in some, ${ }^{9-11}$ but not other studies. ${ }^{12,13}$ In recent years, efforts have been underway to develop and validate instruments to assess EoE activity. Validated instruments are urgently needed in order to standardize the language of EoE activity assessment and, in so doing, to facilitate communication among the various EoE stakeholders, including patients, industry, physicians, and researchers. This standardization will, in turn, allow EoE researchers to define clinically meaningful end-points for use in clinical trials and observational studies, to compare the efficacy of different 


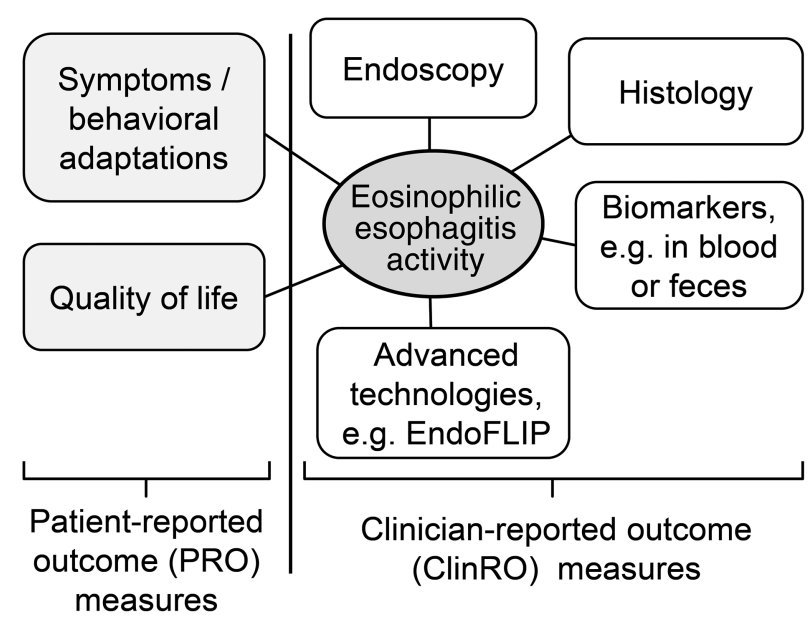

Fig. 1 Capturing all facets of the disease for activity assessment.

therapeutic modalities, and to develop therapeutic algorithms in order to provide patients with the appropriate therapy.

\section{EoE activity assessment: capturing the multiple facets} of the disease

EoE diagnosis is based on two pillars: symptoms and histology. This duality needed for establishing EoE diagnosis points to the fact that overall EoE activity should be assessed by taking into account various patient reported outcomes (PRO) and clinicianreported outcome (ClinRO) measures (Fig. 1).

PRO measures in EoE include those that assess symptom severity, quality of life, and behavioral adaptations to living with dysphagia. Our group has recently shown that EoE patients frequently avoid dense foods, modify the food to ease the swallowing, or take longer to eat a meal. ${ }^{14}$ Evaluating the extent to which patients practice these behaviors represents an integral part of EoE activity assessment. It is important to point out that patients should report their symptoms, behavioral adaptations to living with dysphagia, and quality of life without any help from physicians in order to avoid potential physicianinherent biasing. ${ }^{15,16} \mathrm{ClinRO}$ measures in EoE include assessment of endoscopic, histologic, and laboratory findings, as well as assessment of other aspects of gastrointestinal physiology.

In general, the utility of PRO and ClinRO measures in overall disease activity assessment strongly depends on the impact of the disease-inherent alterations on the PRO measures and availability of suitable biologic measures (e.g. biomarkers) that can be used as indicators of disease severity. We have recently described this concept elsewhere. ${ }^{17}$ In our opinion, both PRO and ClinRO measures contribute in an important way to overall EoE activity. When EoE is untreated, ongoing eosinophil-predominant inflammation results in development of esophageal remodeling and fibrosis. It is well documented that these underlying changes are associated with EoEassociated endoscopic findings, such as stricture(s) and luminal narrowing. ${ }^{18-22}$ Esophageal strictures, in turn, are associated with dysphagia episodes and represent the main risk factor for food bolus impactions and a potential risk for impaction-associated esophageal perforations. ${ }^{23,24}$ Given the fact that in EoE severity of inflammation and stricture formation are associated with symptom severity, both PRO and ClinRO should be used to assess disease activity. ${ }^{17,25}$

\section{Defining end-points for clinical trials}

To date, no EoE-specific pharmacologic therapy has been approved by the United States Food and Drug Administration (US FDA) and the European Medicines Agency (EMA). Nonetheless, several clinical trials that evaluate the efficacy of medications in $\mathrm{EoE}$ patients are currently ongoing. The sponsors of these trials face numerous challenges, and, among them, the lack of EoE-specific instruments that have been deemed by US FDA as qualified for use as end-points in exploratory studies. The US FDA has played an active role in fostering collaborations among different stakeholders in order to develop clinical outcome assessment tools to support drug development and to establish meaningful endpoints to be used in clinical trials, and observational studies. ${ }^{15,16}$ These concerted efforts should ultimately provide EoE patients with much needed therapies.

\section{Challenges in clinical EoE activity assessment}

PRO measures can be separated into instruments that assess symptoms, behavioral modifications, and quality of life. Given the fact that challenges in assessing EoE symptoms and developing PRO instruments are numerous, our discussion is limited to a few aspects that we feel merit particular attention. First, EoE symptom presentation varies with age. ${ }^{1,26}$ Infants and toddlers typically present with feeding difficulties and failure to thrive, whereas school-aged children often present with vomiting and abdominal pain. ${ }^{1,26}$ Adolescent and adult EoE patients mostly suffer from dysphagia and food impactions. ${ }^{1,26}$ This age-dependent symptom presentation should be taken into account when developing instruments to assess clinical EoE activity. For pediatric patients specifically, different PRO instruments should be developed for patients of different ages: instruments that can be completed by older children themselves, and instruments that should be completed by someone other than the patient (a parent, caregiver, or someone, who observes the patient in daily life) for children that are too young to complete the instrument on their own. Second, a distinct time period 


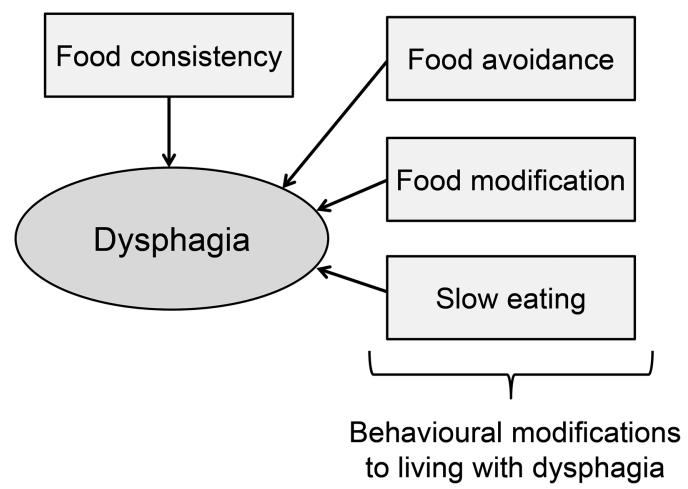

Fig. 2 Factors influencing patient's perception of dysphagia.

has to be defined for patients to recall their symptoms. For clinical trials, regulatory authorities favor the use of a daily electronic diary. However, daily diaries may not be practical for use in settings other than pharmaceutical company-sponsored clinical trials. Third, measuring the severity of the key EoE symptom, dysphagia, strongly depends on the consistency of the ingested food. In practical terms, when asked by a physician, 'Do you have dysphagia?', the patient consuming a diet consisting of mostly soft foods, such as yoghurt and soup, is likely to answer 'No', even in the presence of relatively severe EoEspecific biologic alterations. If such a patient would then be encouraged to eat a more dense food item, such as piece of meat or fresh bread, this patient would be much more likely to report dysphagia. Thus, dysphagia should be assessed in the context of consuming foods of various consistencies. Similarly, behavioral modifications to living with dysphagia, such as avoidance of certain foods, modification of foods to ease the swallowing, and a relatively long time required to eat certain food items, should also be taken into account and assessed in the context of eating foods of various consistencies (Fig. 2).

\section{INSTRUMENTS THAT ASSESS PRO MEASURES IN EoE}

The purpose of this section is to provide an overview of the different EoE-specific PRO instruments published to date (Table 1). Instruments are presented in order of publication from latest to oldest.

\section{Instruments for assessment of clinical activity in adult EoE patients}

\section{EoE Activity Index (EESAI) PRO instrument}

In 2014, the international EEsAI study group published a study on development and validation of the EEsAI PRO instrument. ${ }^{14}$ In the process of the development and validation of the instrument, the group followed recommendations of the US FDA. ${ }^{15}$ Patient $(n=186)$ input on EoE symptoms was sought using a mixed methods approach, consisting of surveys, cognitive individual patient interviews, and focus groups that were guided by a psychologist. The newly created instrument (in paper form) containing items assessing various EoE symptoms was completed by 153 adult EoE patients. The patient global assessment of EoE symptom severity recalled over three distinct periods (24 hours, 7 days, and 30 days) was also collected. Multivariable linear regression analysis and analysis of variance with patient global assessment as an outcome and items of the instrument as predictors was used to obtain an equation for constructing a PRO score by quantifying the extent to which included items explained the variability in patient global assessment. Items addressing various characteristics of dysphagia, behavioral adaptations to living with dysphagia, and pain while swallowing were included in a preliminary version of the score. This score for a 24-hour and 7-day recall period was validated in a second independent group of 120 patients recruited in Switzerland (German and French) and the United States (English). The final score ranges from 0 to 100 points and includes seven items that assess frequency and duration of dysphagia episodes, severity of dysphagia caused by eating foods of eight different consistencies, and behavioral adaptations to living with dysphagia also assessed in the context of eating foods of eight different consistencies. Practicality and content validity were assessed by conducting cognitive debriefings. Patients took a median of 8 minutes (interquartile range 7-9, range 4-10 minutes) to complete the EEsAI PRO instrument and judged the instrument to be easy to complete. ${ }^{14}$ Furthermore, patients considered the EEsAI PRO instrument as adequate in assessing relevant EoE-related complaints (content validity). ${ }^{14}$ The EEsAI PRO instrument, which is copyrighted by the University of Bern, Switzerland, is currently being used in different clinical trials.

\section{Dysphagia Symptom Questionnaire (DSQ)}

In 2013, Dellon et al. published the study on development of the DSQ, a three-item electronic diary. ${ }^{27}$ The diary was developed in collaboration with the Meritage Pharma, Inc. (the copyright holder). In the first phase, 10 adolescent and 10 adult EoE patients were enrolled into face-to-face concept elicitation and cognitive interview sessions in order to create the diary. Adolescent and adult patients with symptoms of dysphagia were enrolled. At the time of the study, esophageal biopsies of these patients had at least 15 eosinophils per high-power field. Solid-foodavoidance days, dysphagia days, and actions taken to get dysphagia relief were recorded. The consistency of solid food was not specified. The scoring algorithm was expert-based and was constructed by giving each item response a discrete value, which were then 
Table 1 Overview of the instruments that assess symptoms and quality of life in adult and pediatric EoE patients

\begin{tabular}{|c|c|c|c|c|}
\hline & $\begin{array}{l}\text { Name of the } \\
\text { instrument }\end{array}$ & Characteristics & Languages & References \\
\hline \multirow[t]{4}{*}{$\begin{array}{l}\text { Clinical activity } \\
\text { in adult EoE } \\
\text { patients }\end{array}$} & $\begin{array}{l}\text { EoE Activity } \\
\text { Index (EEsAI) } \\
\text { PRO } \\
\text { instrument }\end{array}$ & $\begin{array}{l}\text { - Developed using patient input } \\
\text { - Score evaluated in } 153 \text { patients and validated in } 120 \text { patients - } \\
\text { based on patient global assessment } \\
\text { - Recall period: } 7 \text { days and } 24 \text { hours } \\
\text { - Completion time: } 8 \text { minutes } \\
\text { - Content valid }\end{array}$ & $\begin{array}{l}\text { English } \\
\text { German } \\
\text { French }\end{array}$ & $\begin{array}{l}\text { Schoepfer } \\
\quad \text { et al. } .^{14}\end{array}$ \\
\hline & $\begin{array}{l}\text { Dysphagia } \\
\text { Symptom } \\
\text { Questionnaire } \\
\text { (DSQ) }\end{array}$ & $\begin{array}{l}\text { - Developed using patient input } \\
\text { - Field-tested in } 35 \text { adolescent and adult patients } \\
\text { - Expert-based scoring algorithm } \\
\text { - Recall period: } 24 \text { hours (daily electronic diary) } \\
\text { - Content valid }\end{array}$ & English & Dellon et al. ${ }^{27}$ \\
\hline & $\begin{array}{l}\text { Straumann } \\
\text { Dysphagia } \\
\text { Index (SDI) }\end{array}$ & $\begin{array}{l}\text { - Developed using physician input } \\
\text { - Expert-based scoring algorithm } \\
\text { - Recall period: } 7 \text { days } \\
\text { - Evaluated in a RPCT in } 36 \text { patients }\end{array}$ & $\begin{array}{l}\text { English } \\
\text { German }\end{array}$ & $\begin{array}{l}\text { Straumann } \\
\quad \text { et al. }^{12}\end{array}$ \\
\hline & $\begin{array}{l}\text { Mayo Dysphagia } \\
\text { Questionnaire } \\
\text { (MDQ) }\end{array}$ & $\begin{array}{l}\text { - Developed and validated to assess dysphagia in adults with } \\
\text { different esophageal diseases (physician input was used for item } \\
\text { generation) } \\
\text { - Recall period: } 14 \text { days and } 30 \text { days } \\
\text { - Completion time: } 10 \text { minutes } \\
\text { - Content valid } \\
\text { - Evaluated in a RPCT in } 42 \text { adults with EoE }\end{array}$ & English & $\begin{array}{l}\text { Grudell } \\
\text { et al. }{ }^{28} \text { and } \\
\text { McElhiney } \\
\text { et } \text { al. }^{29}\end{array}$ \\
\hline \multirow[t]{4}{*}{$\begin{array}{l}\text { Clinical activity } \\
\text { in pediatric } \\
\text { EoE patients }\end{array}$} & $\begin{array}{l}\text { Clinical } \\
\text { symptom score } \\
\text { (CSS) }\end{array}$ & $\begin{array}{l}\text { - Developed using physician input } \\
\text { - Evaluated in a RPCT in } 71 \text { pediatric patients aged } 2-18 \text { years } \\
\text { - Expert-based scoring algorithm } \\
\text { - Recall period: } 14 \text { days }\end{array}$ & English & Gupta et al. ${ }^{11}$ \\
\hline & $\begin{array}{l}\text { Pediatric EoE } \\
\text { symptom score } \\
\text { (PEESS, } \\
\text { Version 2.0) }\end{array}$ & $\begin{array}{l}\text { - Developed using patient and parent input (children } 2-18 \text { years } \\
\text { of age) } \\
\text { - Only qualitative methods have been published } \\
\text { - expert-based scoring algorithm } \\
\text { - Recall period: } 30 \text { days }\end{array}$ & English & $\begin{array}{l}\text { Franciosi } \\
\text { et al. }^{30}\end{array}$ \\
\hline & $\begin{array}{l}\text { Symptom } \\
\text { scoring tool } \\
\text { (SST) }\end{array}$ & $\begin{array}{l}\text { - Developed using physician input } \\
\text { - Field tested in } 35 \text { EoE patients, } 27 \text { GERD patients and } 38 \\
\text { controls } \\
\text { - Completed by children and parents } \\
\text { - Expert-based scoring algorithm } \\
\text { - Evaluated in a RPCT in } 24 \text { pediatric patients }\end{array}$ & English & Aceves et al. ${ }^{31}$ \\
\hline & $\begin{array}{l}\text { Pediatric EoE } \\
\text { symptom } \\
\text { instruments by } \\
\text { Flood et al. }\end{array}$ & $\begin{array}{l}\text { - Questionnaires for parents of EoE patients } 2-7 \text { years of age and } \\
\text { patients } 8-17 \text { years of age } \\
\text { - Recall period: } 24 \text { hours } \\
\text { - Expert-based scoring algorithm } \\
\text { - Content valid } \\
\text { - Score not validated }\end{array}$ & English & Flood et al. ${ }^{32}$ \\
\hline \multirow[t]{2}{*}{ Quality of life } & $\begin{array}{l}\text { Adult EoE } \\
\text { quality of life } \\
\text { instrument } \\
\text { (EoO-QOL-A) }\end{array}$ & $\begin{array}{l}\text { - Developed using patient input } \\
\text { - Validated in adult EoE patients } 18-70 \text { years of age } \\
\text { - Good internal consistency and test-retest reliability } \\
\text { - Recall period: } 7 \text { days }\end{array}$ & $\begin{array}{l}\text { English } \\
\text { Spanish }\end{array}$ & Taft et al..$^{33}$ \\
\hline & PedsQL module & $\begin{array}{l}\text { - Developed using patient input } \\
\text { - Validated in pediatric EoE patients } 5-18 \text { years of age } \\
\text { - Good feasibility, reliability, test-retest reliability } \\
\text { - Recall period: } 30 \text { days is described in the study, but 7-day recall } \\
\text { is also available }\end{array}$ & English & $\begin{array}{l}\text { Franciosi } \\
\text { et al. }^{34}\end{array}$ \\
\hline
\end{tabular}

Instruments are listed according to the year of publication, with the most recent listed first. RPCT, randomized, placebo-controlled trial.

totaled for each week. This total was divided by the number of days the DSQ was completed. The DSQ score ranges from 0 to 5 . A total 18 adults and 17 adolescents completed the field trial. The DSQ score strongly correlated with the number of dysphagia days $(\mathrm{R}=0.96, P<0.001)$ and showed to be content valid. The DSQ is currently being used in a clinical trial (E Dellon, pers. comm. 2015).

\section{Straumann Dysphagia Index (SDI) instrument}

SDI is a non-validated PRO instrument that was first evaluated in a natural history study by Straumann et al. (published in 2003) and subsequently used, in a modified form, in a randomized, placebo-controlled trial by Straumann et al. (published in 2010) evaluating the efficacy of swallowed topical budesonide in 36 adult EoE patients. ${ }^{12,35}$ The instrument was developed using physician input, and the scoring algorithm for this instrument is expert-based. The SDI assesses the following EoE symptoms: (i) frequency of dysphagia events and (ii) intensity of dysphagia events. The SDI score ranges from 0 to 9 points. Treatment with swallowed topical budesonide significantly reduced esophageal peak eosinophil counts, and the SDI was 
responsive. ${ }^{35}$ A clinical response was defined as a $\geq$ 3-point decrease from the SDI score baseline value. The SDI does not assess dysphagia caused by eating foods of different consistencies and does not take into account behavioral adaptations to living with dysphagia.

\section{Mayo Dysphagia Questionnaire ( $M D Q)$}

The MDQ has been developed and validated by Grudell et al. ${ }^{28}$ The MDQ consists of a total of 28 items. Of these, 17 items assess frequency and severity of dysphagia, 3 items assess the presence of concomitant allergies, 3 items assess the use of acidsuppressive medication, 2 items evaluate the presence of esophageal surgery, 1 item assesses the presence of GERD, 1 item evaluates esophageal dilations, and 1 item evaluates the overall duration of trouble swallowing. Assessment of dysphagia severity is carried out in the context of consuming foods of different consistencies. In addition, patients are also questioned about food modification and time to eat a regular meal. The MDQ aims to evaluate dysphagia in adult patients with different esophageal disorders and has not specifically been developed and validated for adult EoE patients. The reliability and validity of the MDQ, 30-day version (MDQ-30), has been documented in a large population of patients suffering from dysphagia. ${ }^{29}$ The MDQ-30 takes an average of 10 minutes to complete. The MDQ-30 is copyrighted by Mayo Clinics. The MDQ 2-week version, has been used in a double-blind, randomized, placebocontrolled trial evaluating efficacy of fluticasone in 42 adults with a new EoE diagnosis. ${ }^{9}$ The treatment with aerosolized, swallowed fluticasone led to histologic but not symptom response, with response defined as either complete lack of trouble swallowing or decrease in frequency or severity of this symptom.

\section{Instruments for assessment of clinical activity in pediatric EoE patients}

\section{Clinical symptom score (CSS)}

Gupta et al. evaluated the CSS when conducting a randomized, placebo-controlled trial on efficacy of 12-week oral budesonide suspension treatment in a group of 71 pediatric EoE patients between the ages 2 and 18 years old. ${ }^{11}$ The CSS is a newly developed, non-validated symptom score adapted from a previously published symptom scoring tool (SST). ${ }^{36}$ It is based on the physician assessment of the frequency and disruptiveness of multiple symptoms including heartburn, abdominal pain, nocturnal awakening with various symptoms, nausea, regurgitation or vomiting, anorexia or early satiety, dysphagia, odynophagia or food impaction, and the use and disruptiveness of coping behaviors, as determined by questioning the patient and/or caregiver. The CSS does not assess symptoms in the context of eating foods of different consistencies. Each symptom category is scored by the experts on a scale from 0 to 3 points. In order to be scored, the symptom must have been present in the period of the last 14 days before the assessment. The total CSS ranges from 0 to 18 points. A clinical response was defined as a $\geq 50 \%$ reduction in the CSS. Given the fact that a large percentage of placebo-treated patients demonstrated symptom improvement, there was no significant difference in clinical response between oral budesonide suspension treatment groups and the placebo group. ${ }^{11}$

\section{Pediatric EoE symptom score (PEESS)}

In 2011, Franciosi et al. published the study on the qualitative methodology used for the development of the PEESS, version 2.0. ${ }^{30}$ Authors followed the FDA guidelines for PRO development. ${ }^{15}$ The authors conducted of total of 75 interviews with children (ages 8-12 and 13-18 years) and parents (caregivers) (ages 2-4, 5-7, 8-12, and 13-18 years) to construct the PRO instrument. Domains assessing frequency and severity of various symptoms were developed, and open-ended questions were used to generate specific items during the individual focus interviews. This was followed by cognitive interviews for face and content validation. Later on, the instrument construct, instructions, timeframe, scoring, and specific items were reviewed with a separate EoE patient group and their parents during the cognitive interviews. Each item was scored on a scale from 0 to 4 . The symptoms were recalled over a period of 30 days. Results of the field-testing process (evaluation phase) and the validation phase have not yet been published.

\section{Symptom scoring tool}

Aceves $\mathrm{et} \mathrm{al}$. developed and prospectively evaluated a PRO instrument, the so-called SST, to discriminate pediatric patients with EoE from those with GERD or other atopic and non-atopic conditions. ${ }^{31}$ This symptom score is a modified version of the score developed for children with acid-peptic disease. ${ }^{37}$ The instrument was tested in $35 \mathrm{EoE}$ patients (not receiving anti-eosinophil therapies), 27 GERD patients (not undergoing acid suppression), and 38 control patients. The overall symptom score was higher in patients with EoE and GERD when compared with control patients. The SST assesses the frequency and severity of the following groups of symptoms: heartburn/regurgitation, abdominal pain, nausea/ vomiting, anorexia/early satiety, dysphagia, symptom-induced nocturnal wakening, and gastrointestinal bleeding. For each of the seven groups of symptoms, a maximum of 2 points can be given for a most severe for of a symptom. The score ranges from 0 to 14 points. The SST has been developed using physician input and is completed by parents and 
children. The SST does not assess dysphagia caused by eating foods of different consistencies. Authors showed that only dysphagia and anorexia/early satiety could discriminate EoE patients from GERD patients. Dysphagia and anorexia/early satiety also correlated with the severity of EoE-associated histologic and endoscopic findings $(P<0.05) .{ }^{31}$ In a randomized, placebo-controlled trial evaluating the efficacy of oral viscous budesonide treatment in pediatric patients with histologically and clinically active EoE, the authors found that the SST score decreased in the treatment group when compared with placebo $(P=0.031)$ over a 12 -week treatment period. ${ }^{38}$

Pediatric EoE symptom instrument by Flood et al. In 2008, Flood et al. were the first to publish a study on the development of pediatric EoE symptom instruments. ${ }^{32}$ The authors developed the instruments based on a review of the literature and clinical expert consultation. Specifically, the instrument for the parent/ caregiver consists of five items, including those on intensity of pain in the stomach and in the chest, frequency of vomiting, as well as trouble swallowing and pain when drinking and eating. The instrument for children and teenagers consists of six items; in addition to items assessing all the symptoms already described for the parent/caregiver instrument, an item on being bothered by a lump in the throat was included. Each item was scored on a scale from 1 to 5 . They then interviewed (one-to-one interviews) parents of EoE patients aged 2-7 years $(n=12)$ and EoE patients aged $8-17$ years $(n=16)$ about EoE-related symptoms and their impact on everyday life, using open-ended questions, to confirm the appropriateness of the item content of the instruments. Participants then completed the appropriate symptom instruments and were asked to provide feedback on the relevance, comprehensiveness, and clarity of each item. The symptom recall period for the caregiver and the patient instruments was 24 hours. Overall, participants thought that the instruments were clear, relevant, and appropriate for symptom assessment. The instruments did neither assess symptoms in the context of consuming foods of different consistencies nor evaluated behavioral adaptations to living with EoE-related symptoms. The scoring algorithm was based on expert input. Data on the construct validity, reliability, and responsiveness of the measures have not been published to date.

\section{Instruments for assessment of quality of life in adult and pediatric EoE patients}

Adult EoE quality of life (EoO-QOL-A) instrument

In 2011, Taft et al. published a study on development and validation of the first quality of life instrument for adult EoE patients, the adult EoO-QOL-A instru- ment. ${ }^{33}$ A total of 201 patients, between 18 and 70 years of age, participated in the study. Using qualitative methods, the authors studied the disease-specific concerns and their impact on quality of life and identified items for the five following subscales to be included into the EoO-QOL-A instrument: eating/diet impact, social impact, emotional impact, disease anxiety, and choking anxiety. The EoO-QOL-A instrument consists of 37 items. Patients not currently being treated by elimination diets are completing 32 items. A 7-day recall period was chosen to assess impact of EoE on quality of life. The EoO-QOL-A instrument demonstrated excellent internal consistency, split-half and test-retest reliability. The instrument is copyrighted by the Northwestern University (Chicago, IL, USA).

\section{Pediatric quality of life (PedsQL) module}

In 2013, Franciosi et al. published a study on a quality of life instrument for pediatric EoE patients, the so-called PedsQL EoE Module. ${ }^{34}$ The PedsQL EoE Module was completed by 196 pediatric EoE patients and 262 parents. The 33-item PedsQL EoE Module encompasses seven scales, including two symptoms scales (assessing chest/throat/stomach pain, nausea/vomiting, and trouble swallowing), treatment scale, worry scale, communication scale, food and eating scale, and food feelings scale. The recall period for the PedsQL EoE Module utilized in the published study was 30 days. The PedsQL EoE Module scales evidenced excellent feasibility, excellent group comparison reliability across total scale scores, good reliability for the seven individual scales, and excellent test-retest reliability. PedsQL EoE Module scores were worse among patients with active histologic disease (defined as $\geq 5$ eosinophils per highpower field) when compared with those in histologic remission and those treated with dietary restrictions compared with those with no restrictions.

\section{ASSESSING BIOLOGIC MEASURES IN EoE}

\section{Endoscopic activity}

\section{EoE Endoscopic Reference Score (EREFS)} grading system

Hirano et al. have recently published a study on a classification and grading system for endoscopic assessment of esophageal EoE features. ${ }^{39}$ This system, also known as EREFS system, evaluates the severity of the following endoscopic features: exudates, rings, edema, furrows, and strictures. Endoscopic videos from 25 EoE patients and control patients were reviewed by 21 gastroenterologists. Interobserver agreement was assessed by estimating multi-rater $\kappa$ and the proportion of pairwise agreement. The instrument standardizes the long-needed 
common nomenclature and severity grading for the assessment of endoscopic disease activity. The EREFS grading system showed good interobserver agreement among practicing and academic gastroenterologists. The EREFS grading system is not an endoscopic score in the strict sense of the wording. Definitions regarding endoscopic remission, mild, moderate, or severe endoscopic activity have not yet been established.

\section{Histologic activity}

As of yet, no validated histology score for pediatric and adult EoE patients exists. Assessing histologic activity mainly relies on the peak eosinophil count per high-power field. Additional histologic findings, such as basal layer hyperplasia, papillary elongation, eosinophil degranulation, or subepithelial fibrosis, have also been reported as important histologic outcome parameters. In 2007, Dellon et al. have shown that peak eosinophil counts reported in various studies may not be necessarily comparable as different microscope types with different hight power field sizes are used in different studies. ${ }^{40}$ Reporting the observed peak eosinophil counts standardized to $\mathrm{mm}^{2}$ could standardize reporting of peak eosinophils counts in different studies. Similar to the reporting of endoscopic severity, no established definitions of histologic remission, as well as mild, moderate, and severe histologic activity currently exists.

\section{Esophageal string test and Cytosponge}

In order to avoid repetitive endoscopies in EoE patients, several groups have evaluated minimally invasive biologic measures, such as the esophageal string test and the Cytosponge, in order to assess the degree of histologic inflammation.

Furuta et al. have recently published a study on the esophageal string test, a minimally invasive tool to assess mucosal inflammation. ${ }^{41}$ The authors demonstrated that the level of luminal eosinophil-derived proteins extracted from the esophageal string correlated with the esophageal peak eosinophil counts. As such, this test can be considered as a good measure of mucosal inflammation in children with EoE. The esophageal string test will likely be useful in pediatric EoE patients needing repeated assessment of mucosal inflammation to spare these children the burden of repeated endoscopy under general anesthesia.

Katzka et al. compared the accuracy, safety, and tolerability of esophageal sample collection via Cytosponge, an ingestible gelatin capsule containing compressed mesh attached to a string, with those of esophageal biopsies. ${ }^{42}$ Esophageal tissue samples were collected from $20 \mathrm{EoE}$ patients using both Cytosponge and esophageal biopsy sampling during endoscopy. Number of eosinophils per high-power field and levels of eosinophil-derived neurotoxin were determined; hematoxylin and eosin staining was performed. All 20 samples collected by Cytosponge were adequate for analysis. By using a cut-off value of 15 eosinophils per high-power field, analysis of samples collected by Cytosponge identified 11 of the 13 individuals with active EoE (83\%); additional features, such as abscesses were also identified. Numbers of eosinophils in samples collected by Cytosponge correlated with those in esophageal biopsies $(r=0.50$, $P=0.025$ ). Analysis of tissues collected by Cytosponge identified four of the seven patients without active EoE (57\% specificity), as well as three cases of active EoE not identified by analysis biopsy samples. Including information on the level of eosinophil-derived neurotoxin did not increase the diagnostic accuracy. All patients preferred to swallow Cytosponge when compared with undergoing endoscopy. The authors concluded that the Cytosponge is a safe and well-tolerated method for collecting near mucosal specimens.

\section{Measuring esophageal compliance and diameter using endolumenal functional lumen imaging probe}

Uncontrolled eosinophil-predominant esophageal inflammation that persists over time leads to remodeling with formation of strictures. ${ }^{20-24}$ These structural esophageal abnormalities may be detected by the means of endolumenal functional lumen imaging probe that helps physicians to monitor esophageal wall distensibility both to assist in diagnosis of EoE and to track the progress of patients on various treatments. ${ }^{43}$

\section{OUTLOOK}

Described a little over 20 years ago, EoE is still a 'young' disease. Nevertheless, considerable progress has been achieved in this relatively short time interval in regards to our understanding of EoE's natural history, as well as its endoscopic, histologic, and molecular characterization. The common nomenclature for assessing symptoms, quality of life, endoscopic, and histologic activity is about to be standardized. Developing PRO measures in accordance with US FDA guidelines and having these newly developed instruments undergo qualification review by the US FDA remains an important target. We remain hopeful that some of the reviewed instruments will qualify as end-points to be used in clinical trials, and observational studies. This will help all the EoE stakeholders to bring much needed therapies to EoE patients.

\section{References}

1 Straumann A, Spichtin H P, Bernoulli R, Loosli J, Vögtlin J. Idiopathic eosinophilic esophagitis: a frequently overlooked 
disease with typical clinical aspects and discrete endoscopic findings. Schweiz Med Wochenschr 1994; 124: 1419-29. German.

2 Attwood S E, Smyrk T C, Demeester T R, Jones J B. Esophageal eosinophilia with dysphagia. A distinct clinicopathological syndrome. Dig Dis Sci 1993; 38: 109-16.

3 Prasad G A, Alexander J A, Schleck C D et al. Epidemiology of eosinophilic esophagitis over three decades in Olmsted County, Minnesota. Clin Gastroenterol Hepatol 2009; 7: 1055-61.

4 Hruz P, Straumann A, Bussmann C et al. Escalating incidence of eosinophilic esophagitis: a 20-year prospective, populationbased study in Olten County, Switzerland. J Allergy Clin Immunol 2011; 128: 1349-50.

5 Dellon E S, Jensen E T, Martin C F, Shaheen N J, Kappelman M D. Prevalence of eosinophilic esophagitis in the United States. Clin Gastroenterol Hepatol 2014; 12: 589-96.

6 Kapel R C, Miller J K, Torres C, Aksoy S, Lash R, Katzka D A. Eosinophilic esophagitis: a prevalent disease in the United States that affects all age groups. Gastroenterology 2008; 134: 1316-21.

7 Furuta G T, Liacouras C A, Collins M H et al. Eosinophilic esophagitis in children and adults: a systematic review and consensus recommendations for diagnosis and treatment. Gastroenterology 2007; 133: 1342-63.

8 Liacouras C A, Furuta G T, Hirano I et al. Eosinophilic esophagitis: updated consensus recommendations for children and adults. J Allergy Clin Immunol 2011; 128: 3-20.

9 Alexander J A, Jung K W, Arora A S et al. Swallowed fluticasone improves histologic but not symptomatic response of adults with eosinophilic esophagitis. Clin Gastroenterol Hepatol 2012; 10: 742-9.

10 Pentiuk S, Putnam P E, Collins M H, Rothenberg M E. Dissociation between symptoms and histological severity in pediatric eosinophilic esophagitis. J Pediatr Gastroenterol Nutr 2009; 48: 152-60.

11 Gupta S K, Vitanza J M, Collins M H. Efficacy and safety of oral budesonide suspension in pediatric patients with eosinophilic esophagitis. Clin Gastroenterol Hepatol 2015; 13: 66-76.

12 Straumann A, Conus S, Degen L et al. Budesonide is effective in adolescent and adult patients with active eosinophilic esophagitis. Gastroenterology 2010; 139: 1526-37.

13 Dohil R, Newbury R, Fox L, Bastian J, Aceves S. Oral viscous budesonide is effective in children with eosinophilic esophagitis in a randomized, placebo-controlled trial. Gastroenterology 2010; 139: 418-29.

14 Schoepfer A, Straumann A, Panczak R et al. Development and validation of a symptom-based activity index for adults with eosinophilic esophagitis. Gastroenterology 2014; 147: 1255-66.

15 Patrick D L, Burke L B, Powers J H et al. Patient-reported outcomes to support medical product labeling claims: FDA perspective. Value Health 2007; 10 (Suppl. 2): S125-37.

16 Fiorentino R, Liu G, Pariser A, Mulberg A E. Cross-sector sponsorship of research in eosinophilic esophagitis: a collaborative model for rational drug development in rare diseases. J Allergy Clin Immunol 2012; 130: 613-16.

17 Schoepfer A M, Hirano I, Katzka D A. Eosinophilic esophagitis: overview of clinical management. Gastroenterol Clin North Am 2014; 43: 329-44.

18 Hirano I, Aceves S S. Clinical implications and pathogenesis of esophageal remodeling in eosinophilic esophagitis. Gastroenterol Clin North Am 2014; 43: 297-316.

19 Mishra A, Wang M, Pemmaraju V R et al. Esophageal remodeling develops as a consequence of tissue specific IL-5 induced eosinophilia. Gastroenterology 2008; 134: 204-14.

20 Kagalwalla A F, Akhtar N, Woodruff S A et al. Eosinophilic esophagitis: epithelial mesenchymal transition contributes to esophageal remodeling and reverses with treatment. J Allergy Clin Immunol 2012; 129: 1387-96.

21 Rieder F, Nonevski I, Ma J et al. T-helper 2 cytokines, transforming growth factor $\beta 1$, and eosinophil products induce fibrogenesis and alter muscle motility in patients with eosinophilic esophagitis. Gastroenterology 2014; 146: 1266-77.

22 Schoepfer A M, Safroneeva E, Bussmann C et al. Delay in diagnosis of eosinophilic esophagitis increases risk for stricture formation, in a time-dependent manner. Gastroenterology $2013 ; 145: 1230-6$
23 Straumann A, Spichtin H P, Grize L et al. Natural history of primary eosinophilic esophagitis: a follow-up of 30 adult patients for up to 11.5 years. Gastroenterology 2003; 125: $1660-9$.

24 Straumann A, Bussmann C, Zuber M, Vannini S, Simon H U, Schoepfer A. Eosinophilic esophagitis: analysis of food impaction and perforation in 251 adolescent and adult patients. Clin Gastroenterol Hepatol 2008; 6: 598-600.

25 Rothenberg M E, Aceves S, Bonis P A et al. Working with the US Food and Drug Administration: progress and timelines in understanding and treating patients with eosinophilic esophagitis. J Allergy Clin Immunol 2012; 130: 617-9.

26 Noel R J, Putnam P E, Rothenberg M E. Eosinophilic esophagitis. N Engl J Med 2004; 351: 940-41.

27 Dellon E S, Irani A M, Hill M R, Hirano I. Development and field-testing of a novel patient-reported outcome measure of dysphagia in patients with eosinophilic esophagitis. Aliment Pharmacol Ther 2013; 38: 634-42.

28 Grudell A B, Alexander J A, Enders F B et al. Validation of the Mayo Dysphagia Questionnaire. Dis Esophagus 2007; 20: $202-5$.

29 McElhiney J, Lohse M R, Arora A S et al. The Mayo Dysphagia Questionnaire-30: documentation of reliability and validity of a tool for interventional trials in adults with esophageal disease. Dysphagia 2010; 25: 221-30.

30 Franciosi J P, Hommel K A, DeBrosse C W et al. Development of a validated patient-reported symptom metric for pediatric eosinophilic esophagitis: qualitative methods. BMC Gastroenterol 2011; 11: 126.

31 Aceves S S, Newbury R O, Dohil M A, Bastian J F, Dohil R. A symptom scoring tool for identifying pediatric patients with eosinophilic esophagitis and correlating symptoms with inflammation. Ann Allergy Asthma Immunol 2009; 103: 401-6.

32 Flood E M, Beusterien K M, Amonkar M M et al. Patient and caregiver perspective on pediatric eosinophilic esophagitis and newly developed symptom questionnaires. Curr Med Res Opin 2008; 24: 3369-81.

33 Taft T H, Kern E, Kwiatek M A, Hirano I, Gonsalves N, Keefer L. The adult eosinophilic esophagitis quality of life questionnaire: a new measure of health-related quality of life. Aliment Pharmacol Ther 2011; 34: 790-98.

34 Franciosi J P, Hommel K A, Bendo C B et al. PedsQL eosinophilic esophagitis module: feasibility, reliability, and validity. J Pediatr Gastroenterol Nutr 2013; 57: 57-66.

35 Straumann A, Spichtin H P, Grize L, Bucher K A, Beglinger C, Simon H U. Natural history of primary eosinophilic esophagitis: a follow-up of 30 adult patients for up to 11.5 years. Gastroenterology 2003; 125: 1660-69.

36 Aceves S S, Bastian J F, Newbury R O, Dohil R. Oral viscous budesonide: a potential new therapy for eosinophilic esophagitis in children. Am J Gastroenterol 2007; 102: 2271-9.

37 Dohil R, Fidler M, Barshop B et al. Esomeprazole therapy for gastric acid hypersecretion in children with cystinosis. Pediatr Nephrol 2005; 20: 1786-93.

38 Dohil R, Newbury R, Fox L et al. Oral viscous budesonide is effective in children with eosinophilic esophagitis in a randomized, placebo-controlled trial. Gastroenterology 2010; 139: 418-29.

39 Hirano I, Moy N, Heckman M G et al. Endoscopic assessment of the oesophageal features of eosinophilic oesophagitis: validation of a novel classification and grading system. Gut 2013; 62: 489-95.

40 Dellon E S, Aderoju A, Woosley J T, Sandler R S, Shaheen N J. Variability in diagnostic criteria for eosinophilic esophagitis: a systematic review. Am J Gastroenterol 2007; 102: 230013.

41 Furuta G T, Kagalwalla A F, Lee J J et al. The oesophageal string test: a novel, minimally invasive method measures mucosal inflammation in eosinophilic oesophagitis. Gut 2013; 62: 1395-405.

42 Katzka D A, Geno D M, Ravi A et al. Accuracy, safety, and tolerability of tissue collection by Cytosponge vs endoscopy for evaluation of eosinophilic esophagitis. Clin Gastroenterol Hepatol 2015; 13: 77-83.

43 Kwiatek M A, Hirano I, Kahrilas P J, Rothe J, Luger D, Pandolfino J E. Mechanical properties of the esophagus in eosinophilic esophagitis. Gastroenterology 2011; 140: 82-90. 